\title{
Contribution of homeopathy to the control of an outbreak of dengue in Macaé, Rio de Janeiro
}

\author{
Laila Aparecida de Souza Nunes \\ Municipal Secretary of Health, Macaé, RJ, Brazil
}

\begin{abstract}
Homeopathy has contributed throughout history to the control and eradication of epidemic diseases. Facing the challenge of controlling an outbreak of dengue, the Secretary of Health of the county of Macaé, Rio de Janeiro, Brazil, in early 2007 carried out a "Homeopathy Campaign against Dengue". 156,000 doses of homeopathic remedy were freely distributed in April and May 2007 to asymptomatic patients and 129 doses to symptomatic patients treated in outpatient clinics, according to the notion of "epidemic genus". The remedy used was a homeopathic complex against dengue containing Phosphorus $30 \mathrm{cH}$, Crotalus horridus $30 \mathrm{cH}$ and Eupatorium perfoliatum 30cH. The incidence of the disease in the first three months of 2008 fell $93 \%$ by comparison to the corresponding period in 2007, whereas in the rest of the State of Rio de Janeiro there was an increase of $128 \%$. While confounding factors were not controlled for, these results suggest that homeopathy may be an effective adjunct in Dengue outbreak prevention.
\end{abstract}

Keywords: Homeopathy; Collective Health; Epidemics; Dengue

\section{Introduction}

From the 1990s on, the Brazilian public health system underwent deep changes in its political, administrative and organizational structure, allowing for innovation in the planning and management of health-care facilities, including administration of non- conventional medicines. In this context, phytotherapy, homeopathy and acupuncture were included within the practices offered to users of the national public health system (Sistema Único de Saúde - SUS) in Macaé county, state of Rio de Janeiro. The health administration in Macaé has been facing ongoing challenges due to a population growth rate far above that of the state or country. Most of this recent growth has stemmed from rapid development of the local oil industry, attracting immigration from other areas of the state and country, as well as from abroad. This has given rise to an ongoing need to update services, technology, procedures and infrastructure in order to promote health and control disease. The latest outbreak of dengue is a recent example.

\section{Dengue}

Dengue is an acute, tropical, febrile disease caused by a virus belonging to the family of Flaviviridae (which also includes the viruses causing Western Nile fever, Japanese encephalitis and yellow fever). Four Dengue serotypes are known, 1, 2, 3 and 4. The virus is transmitted by Aedes aegypti, and is the most significant arbovirosis affecting human beings, with immense economic and social impact [1].

Transmission from human being to mosquito occurs during viremia, i.e. from one day before fever and until the sixth day of illness. After a female Aedes aegypti mosquito ingests infected blood, the virus replicates in the salivary glands. Within 8 to 12 days and until the end of the life of the mosquito (6 to 8 weeks) the mosquito is capable of transmission. When a human is bitten by an infected mosquito, the virus replicates in the blood creating an incubation period is 3 to 15 days (average: 5-6 days). The course of the disease may be benign or severe, according to the clinical form: subclinical infection, classic dengue (DF), dengue hemorrhagic fever (DHF) and dengue shock syndrome (DSS) [1].

\section{Epidemiology}

The World Health Organization (WHO) estimates that 50 to 100 million individuals are affected annually in more than 100 countries in all continents but Europe [2]. Outbreaks plague Asia, infecting hundreds of thousands of people in Eastern India, Indonesia and the Philippines. DHF was first described in the 1950s in the Philippines and Thailand. In the Americas, Dengue has been reported for more than 200 years. The circulation of the virus increased first in the $19^{\text {th }}$ century and then since the 1960s. Serotypes 2 and 3 have been identified in several countries. From the 1980s on, 
outbreaks occurred in several countries: Cuba (1981), Brazil (1982, 1986-2002), Bolivia (1987), Paraguay (1988), Ecuador (1988) and Peru (1990). The first report of DHF in the Americas was made in Cuba in 1982, caused by serotype 2; the second one, in Venezuela (1989).

In Brazil, there are reports of Dengue fever in São Paulo (1916) and Niterói/RJ (1923). The first clinically and laboratorially documented outbreak occurred in Roraima (1981-1982), caused by serotypes 1 and 4. Ongoing epidemics started in 1986 in Rio de Janeiro and the Northeast area, extending throughout the country [1]. From 2002 to 2006 1,894,013 cases have been reported, affecting mainly the Northeast (40\%) followed by the Southeast area (37\%) [3]. Until April 2008, the Secretary of Health Surveillance of the Ministry of Health had recorded 120,570 cases, $36 \%$ in the state of Rio de Janeiro [4].

The epidemic of dengue plagues the state of Rio de Janeiro: 75,399 cases were reported until April 2008 , affecting mainly individuals $15-49$ years old (55.5\%). The highest number of deaths was observed in children 0 to 15 years old [5]. Although serotypes 1 and 3 were previously identified, in 2008 serotype 2 has also been found. Macaé county presented an outbreak in 2002, followed by a decrease in incidence in 2004 and 2005. 2007 was marked by a recrudescence; the number of reported cases exceeded the accumulated total of the previous 5 years, reaching a peak in April, when 615 cases were reported. Of 1,842 reported cases, more than 1,000 cases have been laboratory confirmed. Typically, population ages 20-34 years old have been most affected. Whereas in 2002 the circulating virus was serotype 3 , in 2005-1006 serotype 1 prevailed. In 2007, both serotypes 1 and 3 appeared.

\section{Homeopathy and epidemics}

Historically, Homeopathy has had a significant role in the control and eradication of infectious epidemic diseases, particularly before the advent of modern sanitation, vaccinations and antibiotics. Homeopathy became particularly popular in the United States and Europe in the $19^{\text {th }}$ century, due to its success in the treatment of several epidemics, including typhus, cholera, yellow fever and scarlet fever [6].

In Brazil, during the outbreak of typhus in Bahia (1925-1926), Rhus toxicodendron was used as a preventive, and countless cures were observed after the use of Arsenicum album, Bryonia alba, Baptisia tinctoria, Carbo vegetabilis, Ipeca, Phosphorus and Rhus toxicodendron [7]. During an epidemic outbreak of meningitis in 1974, 16,640 doses of Meningococcinum $10 \mathrm{cH}$ were applied in oral single doses as a preventive to children younger than 15 years old in the city of Guaratinguetá, São Paulo. Results indicated the effectiveness of the use of the nosode, as the incidence was among the smallest in the state [8].

In 2001, Eupatorium perfoliatum 30cH was applied as a preventive in the county of São José do Rio Preto, São Paulo, to $40 \%$ of the population of the Cristo Rei area, resulting in a dramatic reduction in incidence by comparison to other neighborhoods, suggesting active protection of the population at risk [9-10].

In 2006, an outbreak in Havana and Camaguey, Cuba, was controlled through the use of a homeopathic complex, which evidenced the ability of the latter to decrease the duration of the acute febrile stage and the frequency of DHF and DSS [11].

\section{Homeopathy in Collective Health}

The grounds for the use of homeopathy in collective health are the principle of similarity and an epidemiological notion known as "epidemic genus", initially formulated by Hahnemann, the founder of homeopathy:

“(...) each single epidemic is of a peculiar, uniform character common to all the individuals attacked, and when this character is found in the totality of the symptoms common to all, it guides us to the discovery of the homoeopathic (specific) remedy suitable for all the cases, which is almost universally serviceable in those patients who enjoyed tolerable health before the occurrence of the epidemic (...)" [12].

This notion would be elaborated on by American homeopath J.T. Kent, who stated that the totality of symptoms of a given epidemics corresponds to the nature of the disease and is obtained after observing about 20 cases and recording the symptoms of each one. In this way, the pathognomonic symptoms of the epidemics are identified, i.e. those appearing in all patients, as well as the particular (modalized) and peculiar (individual) ones. Repertory analysis would lead to a group of 7 or 8 remedies known as "epidemic remedies", from which the doctor would choose the most suitable for each individual patient [13].

\section{Aims}

The aims of the present study were to assess the contribution of homeopathy to the control of the outbreak of dengue in Macaé in 2007, as a complementary strategy and significant coadjuvant, seeking to evaluate its effectiveness and to measure the acceptance by the general population.

\section{Methodology}

Two "Campaigns" were carried out, the first in April and the second in November, 2007.

After review of literature, a homeopathic remedy was chosen for use during the 2007 outbreak of 
dengue in Macaé complementing the standard practices for control of the vector, epidemiological surveillance and training of both health workers and the general population. Standard supportive and pharmacological management, as well as clinical follow up were observed, as described in the Manual de Manejo Clínico (Manual of Clinical Management) by the Ministry of Health [14]. The remedy chosen was the complex described by Marino [9-10], the indication of which arose from the application of the notion of "epidemic genus", as the characteristic symptomatic nucleus prevailing in most cases of DF and DHF analogically corresponds to the symptoms of three remedies:

- Eupatorium perfoliatum: represents the prototype of DF.

- Phosphorus: affinity for the liver, which explains its effects on coagulation; moreover, there is liver involvement in all dengue cases.

- Crotalus horridus: analogy to DSS as a function of its effects on vascular permeability, hemoconcentration and circulation failure.

All three remedies were used in homeopathic dilution $30 \mathrm{cH}$, due to the safety guaranteed by a dilution surpassing Avogadro's number, making virtually insignificant the possibility of side-effects [11].

Population in the study included individuals of both genders and all age groups, including pregnant women; special attention was given to individuals with previous contact with the disease. Adherence by the population was spontaneous or voluntary.

The remedy was prescribed in single doses, 2 drops p.o. for prevention purposes. In symptomatic cases suggesting dengue, the patient received at the public outpatient clinic (Unidade Básica de Saúde UBS) a $5 \mathrm{ml}$. vial of homeopathic remedy, to take 5 drops p.o. 3 times a day for one week. Educational materials were distributed among the population, explaining features of homeopathy: composition of remedies, expected effect, target population, sideeffects, corresponding legislation (Rule MS/GM No 971 from May $3^{\text {rd }} 2006$, dealing with the inclusion of homeopathy in study protocols for endemic and epidemic diseases), prevention regarding the mosquito and information on the disease and the fluxogram of treatment. Health workers were specifically trained; a "Routine for the assistance of patients suspected of dengue" included a protocol for the use of homeopathy.

\section{Results}

Between April and May 2007, 156,000 doses of the homeopathic remedy were administered free-ofcharge. The estimated population of Macaé was 180,000 inhabitants. The intention was to diminish individual and collective susceptibility to the disease and minimize symptoms in those already or later ill. The homeopathic remedy for therapeutic purposes was also distributed free-of-charge to 129 symptomatic patients. The administrative cost of the remedies was $R \$ 0.01$ for prevention and $\mathrm{R} \$ 3.50 /$ vial for treatment. $(\mathrm{R} \$ 1,00 \approx \mathrm{US} \$ 0,50$ May, 2007)

In symptomatic patients, disease was diagnosed at the moment of receiving the homeopathic remedy or later, through clinical evaluation. Follow up showed they presented relief of symptoms from the very beginning of treatment and complete remission was earlier (average $=5$ days), without complications, by comparison to patients who did not use homeopathy (average $=8.6$ days). None of the homeopathically treated patients progressed to DHF and only 2 were hospitalized, for intravenous hydration.

During the second stage of the campaign, between November and December 2007, 60,000 doses of homeopathic remedy were distributed. In this instance, attention was particularly paid to those who developed dengue after taking the homeopathic remedy, with outcomes suggesting the effectiveness of homeopathy, as those who fell ill after taking one single preventive doses presented a milder and shorter course.

The homeopathic intervention was followed by a dramatic fall in the number of cases when compared with previous years. (Figure 1) From January to March 2008, 35 cases of dengue were reported in Macaé. In all of them, the disease was benign and no deaths were reported [15].

Annual variation in cases reported in Macaé mirrored the figures reported in the state of Rio de Janeiro from 2000 to 2007, when there was a higher peak in Macaé - triggering the homeopathy campaign. From that moment on, a dramatic fall was recorded, not observed in the remaining localities (Figure 2). The same phenomenon could be observed in the north of the state (where Macaé is located) (Figure 3).

To compare rates with other counties, we chose those in the state of Rio de Janeiro that in January 2007 had an incidence of Dengue similar do Macaé's, i.e. 20 cases $/ 100,000$ residents. (Figure 4) In these counties, Dengue rates rose dramatically between January 2007 and January 2008, whereas the rate in Macaé plummeted by $93 \%$. (Figure 5)

Figure 1. Monthly report of cases of dengue 2002-2007 in Macaé. 


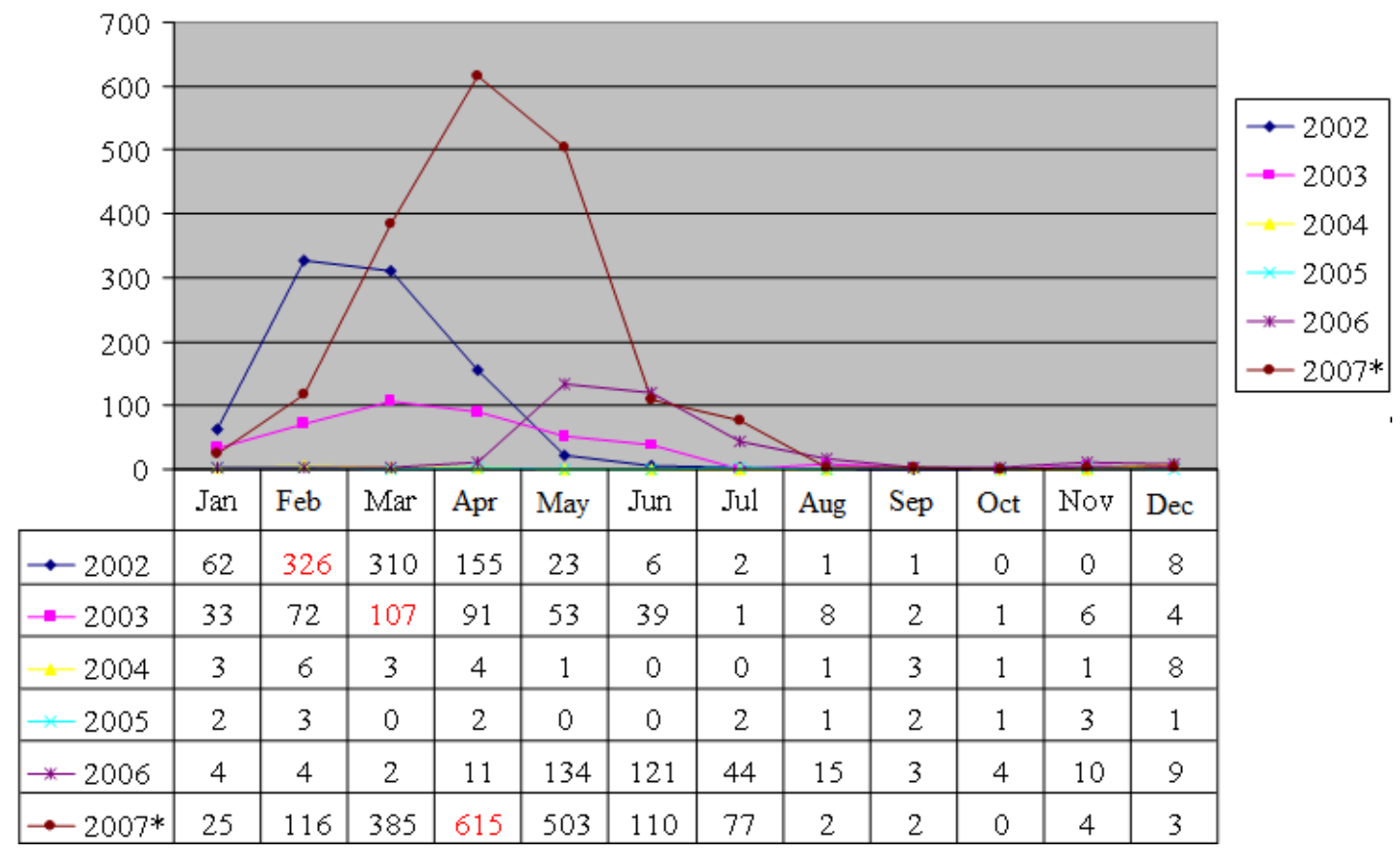

Source: SINAN/Divisão de Informação e Análise de Dados [15].

Figure 2. Report of cases of dengue in the state of Rio de Janeiro, 2000-2008.

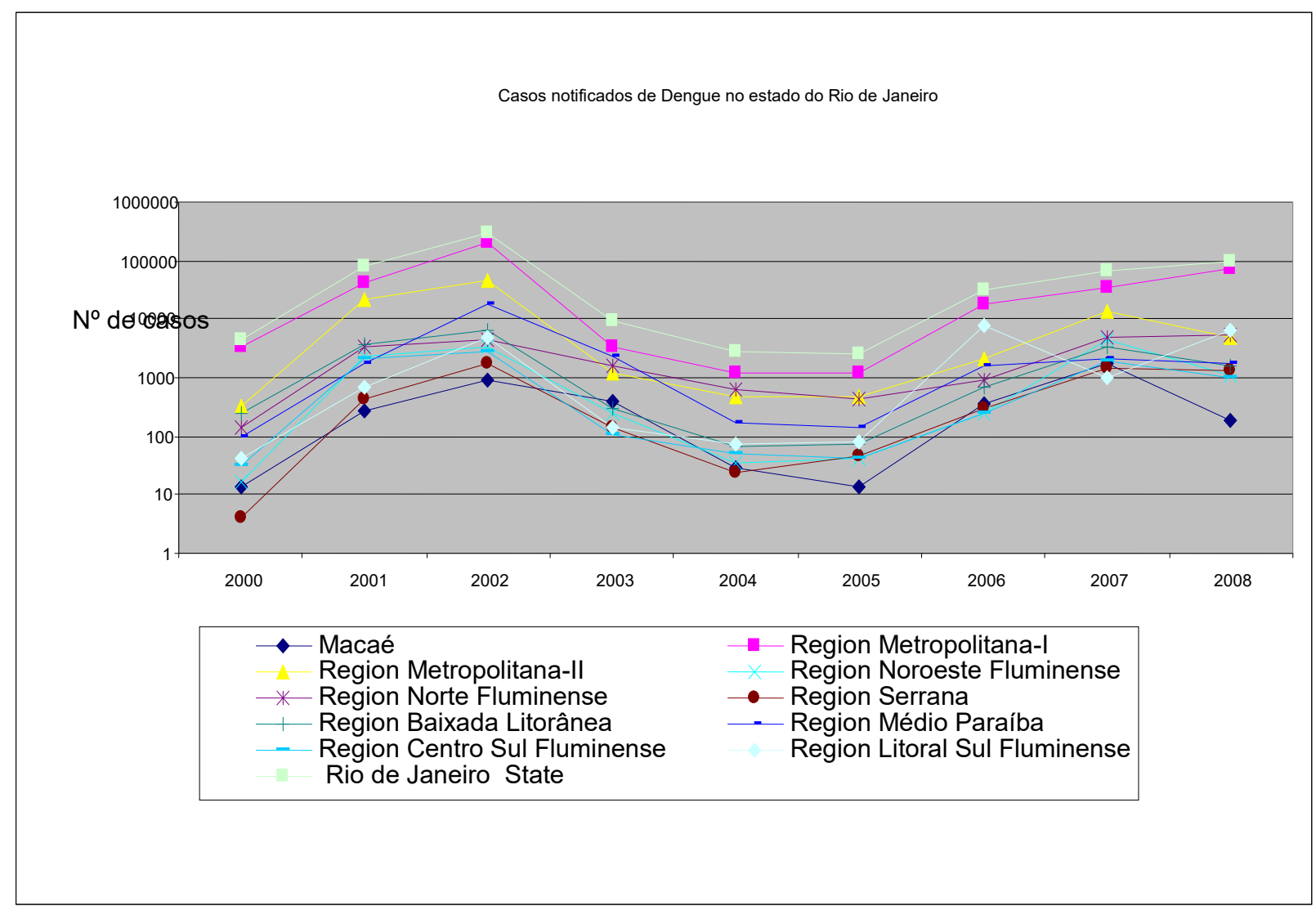

Source: SESDEC-RJ/SAS/SVS/CVE/GDT/GDTVZ [5]. 
Figure 3. Comparison of reported cases among Macaé, Northern Rio de Janeiro state and the overall state of Rio de Janeiro, 1998-2008.

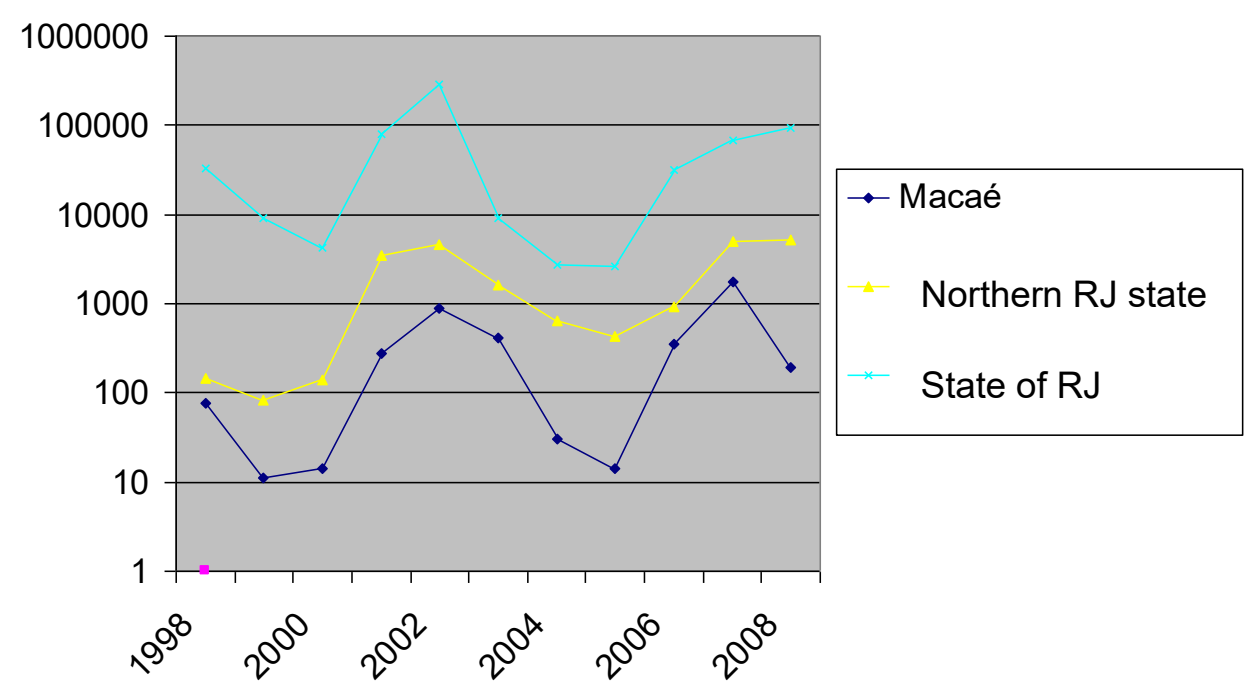

Source: SESDEC-RJ/SAS/SVS/CVE/GDT/GDTVZ.[5]

Figure 4. Comparison of Rio de Janeiro state counties with similar epidemiological profile January - March 2007.

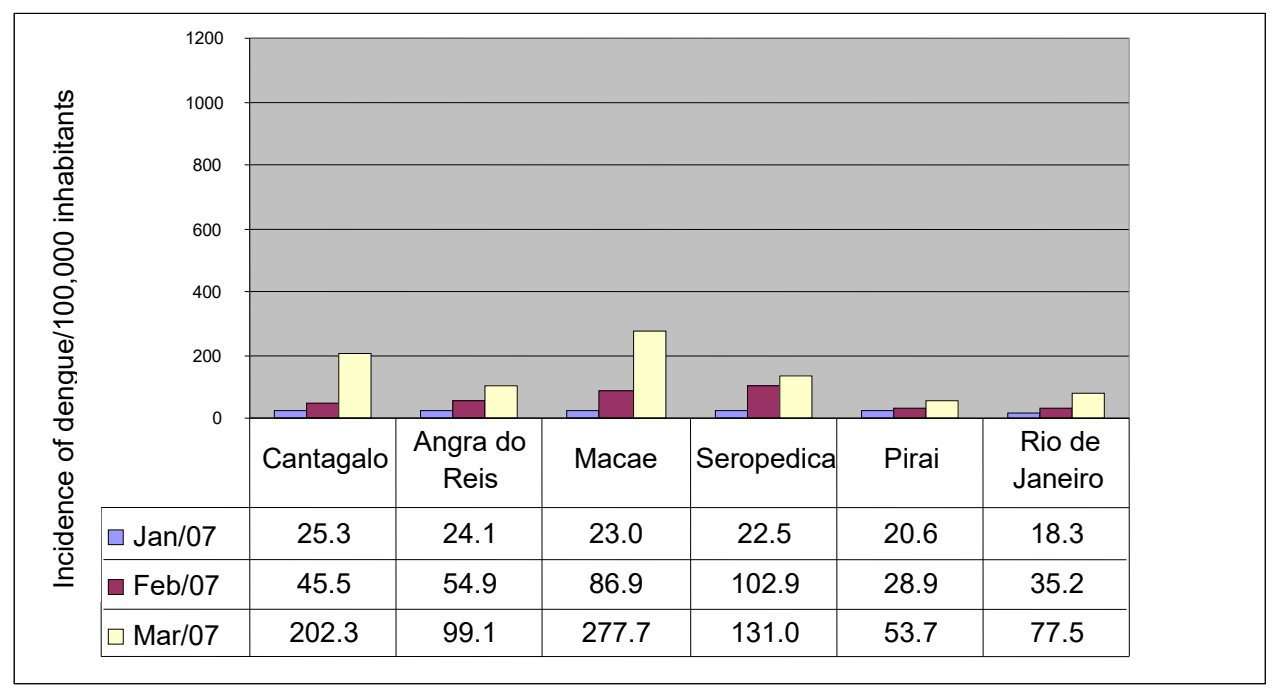

Source: SESDEC/RJ [5].

Figure 5. Report of cases of dengue 2007-2008 in counties with similar epidemiological profiles in January 2007. 


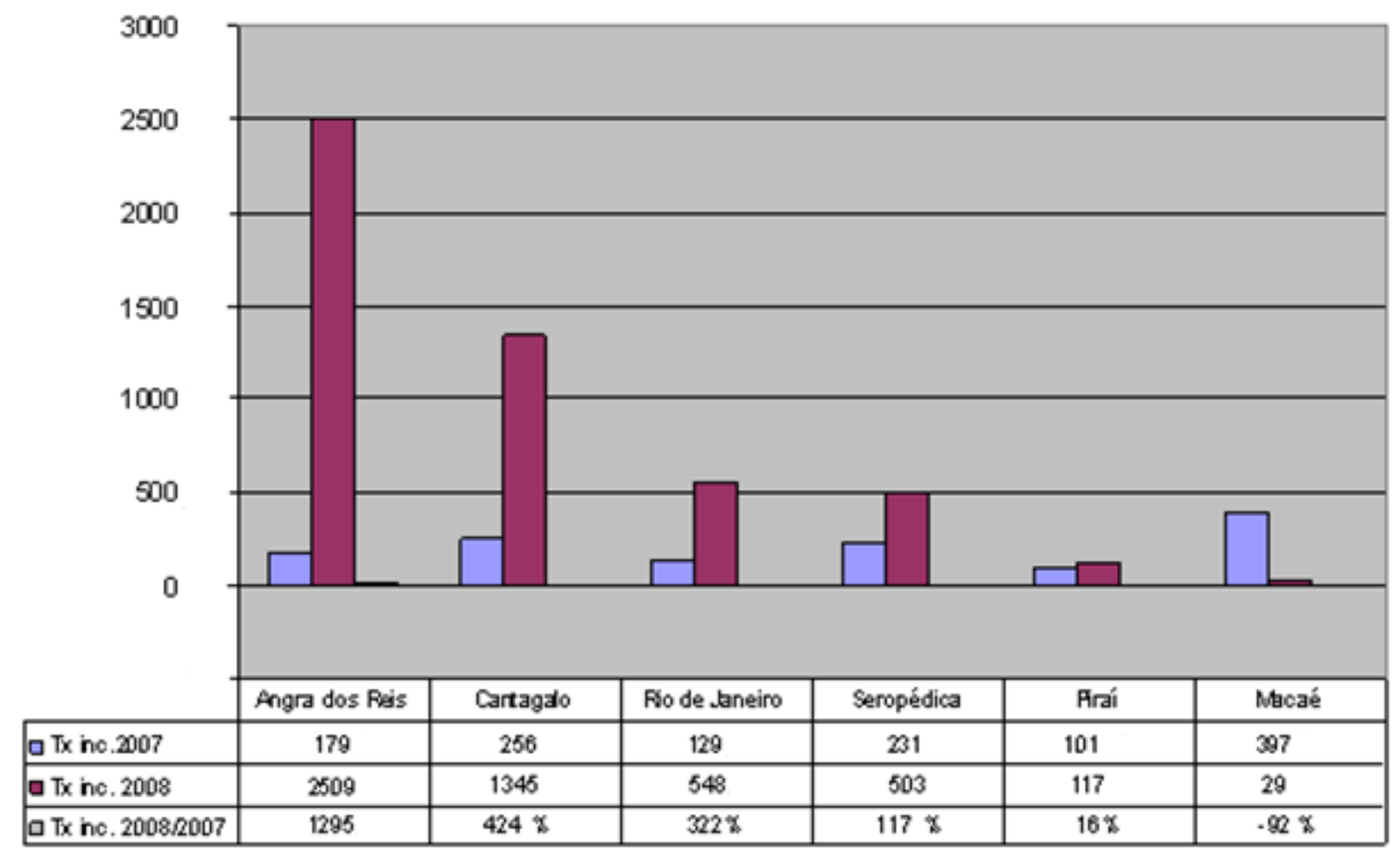

Source: SESDEC/RJ [5]

\section{Conclusions}

The use of homeopathy may be a useful adjunct the control of epidemics, indicating that it can make a significant contribution to public health. It represents a low-cost resource, while its effectiveness is supported by empirical evidence. Moreover, it can be implemented rapidly, as only a short period of time is required from the onset of an epidemic outbreak to the choice of the remedy corresponding to the epidemic genus.

The use of homeopathy in outbreak control complemented more conventional public health actions carried out by the Health Secretary of the county of Macaé, and apparently made a significant contribution to the control of dengue in the county. Homeopathic remedies can help to minimize the progression and severity of the disease and to prevent endemic and epidemic diseases, particularly those where no vaccinations are yet available. It might be emphasized that, the control of dengue requires a combination of strategies, with homeopathy as only one pillar.

With the broadening of access to homeopathic remedies, the compliance of the population was broad, and the project was popularly approved at the county Health Conference. On this occasion, considering that health is an integrated activity, the creation of a Nucleus of Integrative Therapies was approved, providing professional health assistance in homeopathy, acupuncture, phytotherapy, homeopathic and phytotherapic pharmacy.

\section{References}

[1] Brasil, Ministério da Saúde/Secretaria de Vigilância em Saúde. Guia de Vigilância Epidemiológica. Brasília: Ministério da Saúde; 2006.

[2] Brasil, Ministério da Saúde - Vigilância em Saúde [online]. [cited 2008 Apr 18]. Available from: http://www.saude.gov.br.

[3] Brasil, Ministério da Saúde - Vigilância em Saúde [online]. [cited 2008 Jun 06]. Available from: http://www.saude.gov.br.

[4] Brasil, Ministério da Saúde. Nota Técnica de 28/03/08. Brasília: Ministério da Saúde; 2008.

[5] Secretaria Estadual de Saúde e Defesa Civil do Estado do Rio de Janeiro - SESDEC RJ/SAS/SVS/Assessoria de Doenças Transmitidas por Vetores e Zoonoses. Dados SINAN-RJ 04/04/2008 and 16/04/2008. 2008.

[6] Ullman D, editor. Homeopatia: medicina para o século XXI. São Paulo: Cultrix; 1988.

[7] Galhardo JER, editor. Iniciação homeopáthica. Rio de Janeiro: Sondermann; 1936.

[8] Castro D. Homeopatia e profilaxia. São Paulo: Similia; 1980.

[9] Marino R. Homeopatia em saúde coletiva: contribuição ao estudo das epidemias [Dissertation (MSc)]. São José do Rio Preto: FAMERP; 2006. 
[10] Marino R. Homeopathy and Collective Health: The Case of Dengue Epidemics. Int J High Dilution Res [online]. 2008 [cited 2008 Dec 19]; 7(25): 179185. Available from:

http://www.feg.unesp.br/ ojs/index.php/ijhdr/article/ view/312/373.

[11] Secretaria Municipal de Saúde e Higiene da Prefeitura de São José do Rio Preto. Informe Técnico - 21/03/2007. 2007.

[12] Hahnemann, S. Organon da Arte de Curar. São Paulo: Bento Mure; 2002.
[13] Kent, JT. Lições de filosofia homeopática. São Paulo: Organon; 2002.

[14] Brasil, Ministério da Saúde/Secretaria de Vigilância em Saúde Diretoria Técnica de Gestão. Dengue: diagnóstico e manejo clínico. Brasília: Ministério da Saúde; 2005.

[15] Secretaria Especial de Saúde de Macaé SINANNET, Dados vitais. Macaé: Secretaria Especial de Saúde de Macaé ; 2008 Mar 28.

\section{(cc)) BY-NC-ND Licensed to GIRI}

Support: author declares that this study received no funding

Conflict of interest: The author is the Municipal Coordinator of Collective Health, Municipal Secretary of Health, Macaé, Rio de Janeiro.

Received: 21 November 2008; Revised 02 December 2008; Published: 19 December 2008

Erratum: 30 Dec 2008. (http://www.feg.unesp.br/ ojs/zacha_ijhdr/erratum/?v=7\&i=25\&pi=186)

Correspondence author: Laila Aparecida de Souza Nunes, laila.nunes@yahoo.com.br

How to cite this article: Nunes LAS. Contribution of homeopathy to the control of an outbreak of dengue in Macaé, Rio de Janeiro. Int J High Dilution Res [online]. 2008 [cited YYYY Mmm DD]; 7(25): 186-192. Available from: http://www.feg.unesp.br/ ojs/index.php/ijhdr/article/view/315/374. 